\title{
Is It Rational to Assume that Infants Imitate Rationally? A Theoretical Analysis and Critique
}

\author{
Markus Paulus \\ Ludwig-Maximilians-Universität, Munich, Germany
}

\section{Key Words}

Action control $\cdot$ Action understanding $\cdot$ Conceptual analysis $\cdot$ Imitation

\begin{abstract}
It has been suggested that preverbal infants evaluate the efficiency of others' actions (by applying a principle of rational action) and that they imitate others' actions rationally. The present contribution presents a conceptual analysis of the claim that preverbal infants imitate rationally. It shows that this ability rests on at least three assumptions: that infants are able to perceive others' action capabilities, that infants reason about and conceptually represent their own bodies, and that infants are able to think counterfactually. It is argued that none of these three abilities is in place during infancy. Furthermore, it is shown that the idea of a principle of rational action suffers from two fallacies. As a consequence, is it suggested that it is not rational to assume that infants imitate rationally.

Copyright $\odot 2012$ S. Karger AG, Basel
\end{abstract}

For the most part, science proceeds continuously by systematically enlarging and deepening our knowledge of certain phenomena. Occasionally, however, empirical findings suggest a very different and novel perspective on a phenomenon, which might lead to an entirely novel assessment of an area of research [e.g., Kuhn, 1962]. One such novel perspective arose in the last decade in the research area of imitation in infancy. For almost one century, developmental psychologists concentrated on the questions whether infants' ability to imitate is inborn or whether it is the result of learning processes [Baldwin, 1968/1906; Ewert, 1983; Preyer, 1980] and, whenever it appears to be there, what are the specific sensorimotor and low-level cognitive mechanisms that enable and affect infants' ability to imitate [Elsner, 2007; Guillaume, 1925; Jones, 2007; Meltzoff \& Moore, 1977; Paulus, Hunnius, Vissers, \& Bekkering, 2011c; Piaget, 1962; Ray \& Heyes, 2011].

\begin{tabular}{ll}
\hline KARGER & ๑ 2012 S. Karger AG, Basel \\
Fax +41613061234 & $0018-716 \mathrm{X} / 12 / 0553-0107 \$ 38.00 / 0$ \\
$\begin{array}{l}\text { E-Mail karger@karger.ch } \\
\text { www.karger.com }\end{array}$ & $\begin{array}{l}\text { Accessible online at: } \\
\text { www.karger.com/hde }\end{array}$
\end{tabular}

Markus Paulus

Department for Psychology

Ludwig Maximilian University

Leopoldstrasse 13, DE-80802 München (Germany)

E-Mail markus.paulus@lmu.de 
One of the first systematic investigations on the mechanisms underlying imitation was performed by Guillaume [1925]. He suggested that a perceived action might serve as a signal that induces the same action in the infant. This is possible, as perceived and executed action have been related to each other by means of associative learning when the infant executes an action and perceives the visual consequences of his own action. In contrast, according to Piaget [1962], this ability is not based on learned associations between visual percepts and the kinesthetic perceptions of one's own body parts, but on infants' progressing ability to assimilate external objects into their schemata. Insofar as the visually perceived movements of other people resemble infants' own movements, they can be assimilated and reproduced. In the second year of life, infants become able to assimilate actions of others even though they cannot observe these actions when they perform them themselves. This ability is acquired through the coordination and reciprocal assimilation of different schemata, so that the visual percepts serve as indices for the movement and so enable the imitation of the observed action.

Notwithstanding this ongoing discussion about if and how infants are able to imitate others' actions [Jones, 2009; Meltzoff \& Moore, 1977; Paulus, 2011; Ray \& Heyes, 2011; Tissaw, 2007], others recently suggested a much richer interpretation, namely that 12 - to 14 -month-old infants already imitate others' actions rationally. In particular, following the account of teleological reasoning in infancy, it has been proposed that preverbal infants already assess the efficiency of an observed action by applying a cognitive principle, the so-called principle of rational action [Gergely \& Csibra, 2003]. It is said to be a core principle that forms 'the initial state of infant's naïve psychological theory ... that is as yet "uncontaminated" by the associations established later in development' [Csibra, Gergely, Bíró, Koós, \& Brockbank, 1999, p. 262]. This theory suggests that, given an action, infants are able to predict the goal of the ongoing action under the assumption that the action is efficient, and given a goal, infants are able to predict the action that someone will perform to reach his goal [e.g., Csibra et al., 1999; but for a different interpretation of these findings, see Paulus et al., 2011a]. Infants are not only said to be employing this principle to understand others' actions, but also to selectively imitate others' actions according to their efficiency: the 'early imitation of goal-directed actions is a selective, inferential process that involves evaluation of the rationality of the means in relation to the constraints of the situation' [Gergely, Bekkering, \& Kiraly, 2002, p. 755].

This approach has led to great interest in developmental and comparative psychology as it proposed the existence of rather sophisticated cognitive processes in infants. More precisely, these results are of high relevance for neurocognitive theories of human action control and cognitive control [e.g., Hommel, Müsseler, Aschersleben, \& Prinz, 2001; Ridderinkhof, Forstmann, Wylie, Burle, \& van den Wildenberg, 2011; Ridderinkhof, van den Wildenberg, Segalowitz, \& Carter, 2004; Zelazo, Carlson, \& Kesek, 2008], as they would indicate the presence of sophisticated cognitive control processes and action selection capacities early in development before they are shown in other tasks [Beck, Riggs, \& Gorniak, 2009; Klossek, Russell, \& Dickinson, 2008; Zelazo, Müller, Frye, \& Marcovitch, 2003].

In the sections that follow, I first present the key finding of so-called rational imitation in greater detail. Thereafter, I employ Brandom's [1994, 2009] notion of implicit commitments and inferential roles to assess the implicit theoretical assumptions inherent in the claim that infants' imitation is rational. The aim of this analysis is to explicate these implicit theoretical commitments, allowing for a subsequent as-

108 Human Development Paulus


sessment of the empirical support for these commitments, which we need to make if we accept this claim. I will discuss three of these implicit commitments (commitments about the existence of particular cognitive abilities) in greater detail and argue that, given the current state of research, none of these cognitive prerequisites are in place in 1-year-old infants ${ }^{1}$. Additionally, applying Hacker's [Bennett \& Hacker, 2003; Hacker, 2010] theoretical considerations about fallacies in cognitive science, I will present a critical analysis of the logical status of the principle of rational action. This analysis suggests that the introduction of the principle of rational action into developmental theorizing leads to severe conceptual confusions. I will conclude that it is not rational to assume that infants imitate rationally.

\section{Rational Imitation in Infancy: The Theory}

The theoretical considerations based on the account of teleological reasoning in infancy have also been applied to research on infants' imitation. In a widely noted study, Gergely and colleagues [Gergely et al., 2002] presented two groups of 14-monthold infants with a model bending over a lamp on a table. When she touched the lamp with her forehead, a light was turned on. In one condition, the model held a blanket in her hands while performing the head touch (hands occupied condition). In the other condition, the model had the blanket loosely hanging around her shoulders. Her hands were on the table while executing the head action (hands free condition). The authors found that more infants imitated the head touch in the hands free compared to the hands occupied condition. They concluded that the infants in the hands free condition thought that the model must have had a good reason to perform the head action; otherwise she would have used her hands [Gergely, Bekkering, \& Kiraly, 2001]. Based upon this consideration, infants also performed the head touch in the hands free, but not in the hands occupied condition and thus imitated the model's action rationally. Motivated by this finding, others also reported evidence of rational imitation in infants [Kiraly, 2009; Schwier, van Maanen, Carpenter, \& Tomasello, 2006; Zmyj, Daum, \& Aschersleben, 2009], chimpanzees [Buttelmann, Carpenter, Call, \& Tomasello, 2007, 2008] and dogs [Range, Viranyi, \& Huber, 2007; but for an alternative explanation in dogs, see Kaminski et al., 2011]. Eventually, this rich interpretation of infants' imitation has been widely accepted in developmental science [Baker, Saxe, \& Tenenbaum, 2009; Csibra \& Gergely, 2009; Gopnik \& Schulz, 2004; Luo, 2010; Nielsen, 2006; Rakoczy, 2008; Siegal \& Varley, 2008; Tomasello, Carpenter, Call, Behne, \& Moll, 2005].

A closer analysis of the line of reasoning shows that the argument that infants imitate rationally is based on the following logic: when the participants observe the model's action, they recognize the model's goal (e.g., illuminating the light) as well as the means that the model chose to attain that goal. By considering the situational constraints and the model's action capabilities in the situation, participants assess

\footnotetext{
${ }^{1}$ It is important not to conflate conceptual and empirical issues [Harr \& Tissaw, 2005]. To this end, the analysis of implicit commitments will proceed in two steps. First, a conceptual analysis will reveal on a theoretical level the implicit commitments inherent in the claim that infants imitate rationally. Second, on an empirical level, a comparison with the literature will show that these commitments (that present themselves as developmental prerequisites) are not likely to be met.
}

Is It Rational to Assume that Infants Imitate Rationally?
Human Development 2012;55:107-121 
the relative efficiency of the action and are thus able to recognize when the model would have been able to perform a more efficient action. If the model has not chosen the most efficient action, infants are surprised, as they reason that the model could have acted more efficiently (e.g., could have used her hands to turn on the lamp) [Gergely et al., 2001]. Therefore, they infer that the model must have had a good reason to use the more inefficient action. Consequently, they decide to imitate the same action.

Explicating the logic of argumentation in this way allows a closer evaluation of the validity of the suggested interpretation of the empirical findings. In particular, it enables an assessment of the implicit theoretical assumptions inherent in the claim that infants' imitation is rational and thus an assessment of the theoretical commitments that we make if we accept this claim [for a detailed analysis on the relation between explicit statements and implicit commitments, see Brandom, 1994, 2009]. In other words, every statement and every judgment rests necessarily on some implicit assumptions as our concepts and propositions are embedded in a network of semantics [Brandom, 1994; van Quine, 1960]. Every time we make a particular statement, we automatically commit ourselves to a number of other statements that we, with some degree of necessity, need to accept. To give a simple example: if we make the statement that A (that we just saw) is a cat, we automatically commit ourselves to the proposition that $\mathrm{A}$ is an animal, has 4 legs and so forth. We cannot deny that $\mathrm{A}$ is an animal, and concurrently propose that $\mathrm{A}$ is a cat. At the same time, if we have qualified doubts that $\mathrm{A}$ is an animal, we are not entitled to state that being is a cat.

Usually, most commitments remain implicit and are not explicated. One reason for this is that the commitments are often self-evident. For example, there is plenty of research on children's developing ability to recognize faces [Nelson, 2001]. Every statement about the precise age when children become able to recognize faces and which features they use to recognize faces rests on the implicit assumption that children are able to process visual information. This assumption, however, is largely selfevident and therefore a detailed explication of such an assumption and similar ones is probably of less interest to developmental psychology.

However, the proposition that particular empirical findings should be interpreted as evidence for the claim that infants imitate rationally is a different case. Here it is rather unclear to which implicit commitments one is obligated when he accepts the proposition that infants imitate rationally. Lacking this knowledge, it is hard to evaluate whether one is ready to make these (implicit) commitments (i.e., whether these implicit commitments are themselves propositions that are qualified). In other words, if a closer analysis of the claim that infants imitate rationally would show that this proposition rests on implicit commitments, which are very problematic and unlikely given the current state of research, then the proposition itself would lack credibility. That is, such an analysis can help us to decide whether or not it is rational to claim that infants imitate rationally.

\section{Three Assumptions Made by the Proponents of Rational Imitation in Infancy}

Applying this approach to psychology allows us to explicate the psychological abilities and mechanisms that must be in place when we credit an organism with another ability. To put it in different words, every cognitive ability rests on some per-

Human Development
$2012 ; 55: 107-121$ Paulus


ceptual and cognitive requirements [Müller \& Giesbrecht, 2008; Overton, 1998; Piaget, 1954], and every time we credit an organism with this ability, we must also credit him with the other abilities. To pick up the previous example, when we credit an organism with the ability to use particular visual features to recognize faces, we must necessarily credit him with the ability to process visual information. If we think that it is rather unlikely that this organism is able to process visual information, it is not rational to propose that he is able to use particular visual features to recognize faces.

Following this logic, I will analyze the essential cognitive prerequisites that an organism must meet to be credited with the ability to imitate rationally. In the following sections, I will argue that the ascription of the ability to imitate rationally to infants rests on at least three assumptions: (a) that infants are able to perceive others' action capabilities, (b) that infants reason about their own and others' bodies, and (c) that preverbal infants engage in counterfactual reasoning. I will argue that each of these assumptions is unlikely given the current state of research. Thus, as infants do not possess the necessary cognitive abilities, I suggest that it is not rational to ascribe to preverbal infants the ability to imitate rationally.

\section{Assumption: Infants Are Able to Perceive Others' Action Capabilities}

First, the ability to imitate rationally requires the ability to perceive others' action capabilities. In other words, to be able to evaluate whether someone has acted in the most efficient way for him to attain a goal, we need to know if he would have been able to perform another action to reach the same goal. In other words, if we were to believe that infants reasoned that the other person could have used another means (e.g., his hands instead of his head), we logically need to assume that infants are able to perceive which actions the other person can or cannot perform. If infants are not able to perceive which actions a person can and cannot perform, they are not able to calculate the relative efficiency of the available means (or to be more surprised when somebody uses his head to turn on a lamp when his hands are available vs. when his hands are not available). The same logic holds if we look at a situation in which infants are supposed to reason that another person has used the most efficient means to attain his goal. If we credit infants with this type of reasoning, we must assume that infants were able to perceive the action capabilities of the person, compute the efficiency of each of his abilities, and then decide if the person has indeed used the most efficient of his available action capabilities. This means that the ability to rationally imitate rests logically upon the ability to assess others' action capabilities. Consequently, if we credit infants with the former ability, we also have to credit them with the latter ability.

The claim that infants imitate rationally, however, is problematic as we have no evidence that 1-year-old infants are already able to adequately assess others' action capabilities. Rather, recent experimental evidence has shown that children up to the age of 2.5 years have difficulties understanding what another person can or cannot do [Paulus \& Moore, 2011]. In a number of different situations, 2.5-, 3.5- and 5-yearold children had to choose nonverbally (e.g., by pointing) between a physically able or unable person to provide help (e.g., between a small and a tall person to retrieve an object from a high cupboard, or a one-handed or two-handed person to transport

Is It Rational to Assume that Infants Imitate Rationally?
Human Development 2012;55:107-121 
a basket with two handles [Paulus \& Moore, 2011]). This study showed that even though children from 3 years of age and up are able to understand whether someone else is able to do something or not, they are not able to adequately reason about others' action capabilities before 5 years of age (e.g., use knowledge about action capabilities to justify why someone should be asked for help and not another person). This suggests that the ability to perceive others' action capabilities in a number of different situations does not develop before the age of 3 and that the ability to reason about others' action capabilities develops even later. However, if infants do not possess the ability to adequately assess and reason about others' action capabilities and if this ability is a necessary cognitive requirement to imitate rationally, it follows that it is unlikely that infants imitate rationally.

Yet, one might argue that research by Hamlin and colleagues [Hamlin, Wynn, \& Bloom, 2007] as well as Kuhlmeier and colleagues [Kuhlmeier, Wynn, \& Bloom, 2003] provides evidence that infants are susceptible to others' action capabilities as they seem to be able to evaluate the prosociality of animated geometrical shapes towards each other [Kuhlmeier et al., 2003] and even show a preference for the previously more prosocial geometrical shape in a preferential reaching task [Hamlin et al., 2007]. Concretely speaking, they prefer to reach to a shape that previously seemed to 'help' another shape than to a shape that previously 'hindered' another shape. However, it should be noted that in these studies infants do not need to be able to evaluate others' action capabilities, but rather the agents' actual behavior (e.g., helping or hindering). The ability to evaluate whether an agent behaves prosocially or not is not necessarily based on the ability to evaluate the agent's exact action capabilities.

It should be noted that a set of interesting studies has suggested that chimpanzees also imitate rationally [Buttelmann et al., 2007, 2008]. However, research that was carefully designed to examine chimpanzees' ability to perceive others' action capabilities has shown that chimpanzees lack this ability [Vonk \& Subiaul, 2009]. In their study, Vonk and Subiaul presented chimpanzees in 5 different experiments with tasks that either required the experimenter to use his hands or his feet to move a food tray to the chimpanzee. In every task, 2 experimenters were present whose arms or feet were not visible or were restrained. Systematically manipulating several factors (such as the kind of restraint, the presence of the body parts, the amount of body surface that was visible, or the distance between chimpanzee and experimenter), the authors showed that the chimpanzees were unable to request the tray of food from the correct experimenter, that is, the one who was able to pass it to them. This suggests that they are not able to perceive others' action capabilities. Given these results, it remains puzzling that chimpanzees should be able to judge the relative efficiency of means and imitate rationally if they are not able to assess others' action capabilities.

\section{Assumption: Infants Reason about Their Own and Others' Bodies}

Second, to be able to imitate rationally, one has to be able to conceptually represent and, especially, reason about one's own body. Different from approaches that suggest that imitation is based on a relatively automatic perception-action matching mechanism [e.g., Heyes, 2001; Meltzoff \& Moore, 1997; Paulus et al., 2011c], rational imitation rests upon the ability to draw inferences about the relative efficiency of different body parts under different circumstances and about which of one's own body

112 Human Development Paulus


parts to use to attain the goal in a subsequent imitation phase. In other words, first one has to draw an inference about the relative efficiency of others' use of particular body parts. Second, one needs to relate the result of this consideration process to the respective parts of one's own body. If one, for example, comes to the conclusion that the other's use of his back to turn on a lamp ('sit-touch') must be the most efficient means to perform this action, one must be able to relate the other's back to one's own when one wants to imitate the action. This requires that one be able to represent not only the other's body parts in a conceptual way, but also one's own, as one needs to relate the conclusion of the inference to the respective body part. In other words, this requires that the first- and third-person perspective be integrated into a scheme that can likewise be applied to oneself and others [Barresi \& Moore, 1996; see also Jones \& Yoshida, 2011]. This means that the ability to rationally imitate rests conceptually upon the ability to represent one's own body in a conceptual way and to relate others' body parts to one's own.

This assumption, however, is problematic. Whereas infants learn from early on about the action-relevant properties of their bodies [Adolph \& Avolio, 2000; Adolph \& Berger, 2006] and the consequences of their own actions [e.g., Verschoor, Weidema, Biro, \& Hommel, 2010] and can use this information to control their own actions [Hommel, 2009a, b], research has shown that only late in the second year of life do children become aware of objective characteristics of their own bodies [Brownell, Zerwas, \& Ramani, 2007; Moore, Mealiea, Garon, \& Povinelli, 2007]. More importantly, up to their third year of life, children have difficulty explicitly representing their own body topography (i.e., its shape, structure, and size) [Brownell, Nichols, Svetlova, Zerwas, \& Ramani, 2010]. In other words, whereas infants possess some action knowledge concerning their own action capacities (e.g., whether they are big enough to fit through a narrow hole or not), teleological reasoning about others' actions requires a body schema that would allow reasoning about the efficiency of the body parts of another person and to relate the result of this logical reasoning process (i.e., the conclusion of the inference) to one's own body. This differs from rather implicit action knowledge of what to do in which situation [see the related discussion of knowing how versus knowing that; Ryle, 1949].

For example, in one of their tasks, Brownell and colleagues [2010] investigated children's knowledge of where specific body parts that were shown on another person were located on their own bodies. They asked 20 - and 30-month-old children to place stickers on their own body parts after they had observed another person placing stickers on those locations of a third person. They found that the 20 -month-old children performed correctly only in about $20 \%$ of the cases, whereas the 30 -month-old children performed correctly in $35-50 \%$ of the cases. These findings suggest that a common representation of the other's and one's own body does not emerge before the second half of the second year of life [Brownell \& Koop, 2007; Moore, 2006] and continues to develop over the preschool period. However, if young children do not possess a common representation of their own and the other's body, it is puzzling that they should be able to relate the conclusion of their inference about the efficiency of an observed action to their respective body part. More specifically speaking, if children up to the age of 3 years have severe difficulties relating another's body parts to their own body parts, it remains mysterious how young infants should be able to do so. It is thus unlikely that 1-year-old infants already engage in rational reasoning about the efficiency of others' actions and imitate others' behavior on the basis of efficiency.

Is It Rational to Assume that Infants Imitate Rationally?
Human Development 2012;55:107-121 


\section{Assumption: Infants Engage in Counterfactual Reasoning}

Third, rational imitation requires the ability to employ counterfactual reasoning, as one needs to assess what someone could have done. In the head touch imitation task [e.g., Gergely et al., 2002], children observed in the hands free condition how the model turned on the lamp with her head while her hands were free. It was suggested that after the children identified the goal of the person (i.e., eliciting the light effect), they realized that the person could have acted differently (i.e., she could have used her hands to turn on the lamp). As a consequence, infants inferred that the model had a good reason for using her head and subsequently imitated the head action. This explanation is based on the assumption that the infants were able to engage in reasoning about counterfactual possibilities, as infants were said to assess what the model could and should have done, even though she performed another action. To put it in the words of Perner and colleagues, underlying this difference between conditions must be infants' counterfactual conditional reasoning: 'If the model had had her hands free, she would have used her hands, instead of her head, to trigger the blinking' [Perner, Sprung, \& Steinkogler, 2004]. That is, the ability to imitate rationally rests conceptually upon the ability to engage in counterfactual reasoning.

This assumption, however, is problematic. Recent research has shown that children up to the age of 5-6 years have difficulty reasoning counterfactually about hypothetical situations [e.g., Beck, Robinson, Carroll, \& Apperly, 2006; Rafetseder, Cristi-Vargas, \& Perner, 2010]. In one of their experiments, for example, Beck and colleagues [2006] presented two groups of 3- to 4- and 5- to 6-year-old children with a device in which a ball was travelling down a tube that was split halfway to provide two possible exits. In one of the trials, the ball was inserted into the tube, rolled down the track, and consequently reappeared at one of the exits. Subsequently, children were asked if the ball could have gone anywhere else. Even though performance was facilitating this task, as the possible exits of the balls were limited and children were familiarized with the tube before the experiment started, young children had considerable difficulty engaging in counterfactual reasoning: the 3- and 4-year-old children answered correctly in only $66 \%$ of the trials (by $50 \%$ chance performance), whereas the 5 - and 6 -year-old children did so in $83 \%$ of the trials. Therefore, if even under facilitated conditions 3 - to 4-year-old children have problems with open counterfactual reasoning, it is puzzling that 12- to 14-month-old infants are said to be able to display this ability in a task in which the alternative possibilities are not explicitly demonstrated (i.e., showing that the lamp could also be turned on using the hands) before the experiment started. Thus, if counterfactual reasoning is a necessary cognitive requirement for rational imitation, it follows that it is unlikely that infants imitate rationally.

One could object that a number of recent studies provided evidence for early false-belief reasoning in infants [e.g., Knudsen \& Liszkowski, 2012; Kovács, Téglás, \& Endress, 2010; Onishi \& Baillargeon, 2005] and that the presence of false-belief reasoning shows, therefore, some sensitivity to counterfactual situations already in preverbal children. However, a number of theoretical models posited that these early competencies in false-belief tasks are most likely not subserved by belief attribution, but other mechanisms [e.g., Apperly \& Butterfill, 2009; De Bruin \& Newen, 2012; Perner \& Ruffman, 2005; Rakoczy, 2012; Sodian, 2011]. The first empirical results have provided evidence for these alternative explanations [Thoermer, Sodian, 
Vuori, Perst, \& Kristen, 2012]. Furthermore, it should be noted that some theory-ofmind researchers have denied a theoretical relation between false-belief reasoning and counterfactual thinking [Perner et al., 2004], questioning whether these findings actually provide evidence for infants' ability to engage in counterfactual reasoning.

\section{Conclusion}

In conclusion, the theoretical analysis of the claims made by the proponents of rational imitation in infancy identified 3 cognitive prerequisites on which the ability to imitate rationally must rest ${ }^{2}$. Importantly, empirical research suggests that none of these cognitive prerequisites are in place in 1-year-old infants. However, if these conceptual preconditions are not met, we cannot ascribe the ability to imitate rationally to infants. That is, even though the behavior of younger children seems to indicate the presence of complex cognitive processes from an adult point of view, the sociocognitive mechanisms underlying this behavior may differ (see error by analogy [Bering \& Povinelli, 2003; Povinelli, Bering, \& Giambrone, 2000; Povinelli \& Giambrone, 1999; see also Haith, 1998]). In other words, even though on a performance level infants' behavior seems to resemble adults' performance, the underlying processes are probably not the same [Moore, 2006; Müller \& Giesbrecht, 2008]. It is therefore much more likely that the behavioral patterns reported by studies that claimed support for rational imitation in infancy can be explained by other 'lowlevel' mechanisms that have been proposed as alternative explanations in the literature, such as motor resonance [Paulus, Hunnius, Vissers, \& Bekkering, 2011b, c].

Paulus and colleagues [2011b] suggested that infants' selective imitation of the head action is not due to the perceived efficiency of the demonstrated action, but to differences in the amount of motor resonance (i.e., motor activation during action observation) between the conditions. They observed that when imitating the head touch, infants always put their hands on the table next to the lamp to maintain a stable position. The action modeled in the hands free condition more closely resembled (compared to the hands occupied condition) the action as the infants performed it themselves. As it has been found that the observation of an action that is part of one's own motor repertoire leads to higher activation in the motor system (i.e., motor resonance) than the observation of an action that is not within one's motor repertoire (e.g. Calvo-Merino, Glaser, Grezes, Passingham, and Haggard [2005]), Paulus et al. [2011b] suggested that the observation of the head action in the hands free condition induced more motor resonance in the observing infant than the action demonstrated in the hands occupied condition. While this explanation suggests an important role for sensorimotor processes in early imitation, it remains a question for future research how more complex forms of imitation evolve out of these simple forms [Jones, 2009; for a general discussion of the developmental aspect, see Adolph \& Robinson, 2008; Barresi \& Moore, 1996; Carpendale \& Lewis, 2004; Heyes, 2009; van Geert, 2004].

\footnotetext{
2 These 3 cognitive prerequisites are not to be meant exhaustive, that is, it is possible and likely that other mechanisms and abilities are also involved in rational imitation. Additionally, these abilities themselves also rest on a range of other processes and mechanisms and are not meant to be modular abilities.
}

Is It Rational to Assume that Infants Imitate Rationally?
Human Development 2012;55:107-121 


\section{What Is the Logical Status of the Principle of Rational Action?}

The main purpose of this contribution was an analysis of the hypothesis that infants imitate rationally. Extending this analysis, the final section will be dedicated to a logical evaluation of the principle of rational action itself, which is suggested to be the cognitive mechanism subserving infants' rational imitation, by means of a conceptual analysis [for the fruitfulness of such an analysis, see Benett \& Hacker, 2003; Nachev \& Hacker, 2010]. The aim of this evaluation is twofold. First, it will be shown that the introduction of this principle in developmental theory formation leads to two problems or fallacies. Second, it aims to show that speaking about a principle of rational action as the underlying cause of infants' ability to evaluate the efficiency of others' actions leads to the problem that one easily overlooks the implicit assumptions inherent in this proposition (as outlined above).

Following the teleological reasoning theory, it has been suggested that infants assess the efficiency of an observed action by applying the principle of rational action [Csibra \& Gergely, 2007]. More precisely, it has been suggested that infants understand others' actions 'through the principle of rational action, which assumes that actions function to realize goal-states by the most efficient means available' [Gergely \& Csibra, 2003, p. 287]. Moreover, this principle is seen as the cognitive mechanism subserving infants' assessment of others' actions as they 'can evaluate the relative efficiency of means by applying the principle of rational action' [Gergely \& Csibra, 2003, p. 291].

However, this view suffers from two fallacies. The first one is that an ability that is normally ascribed to a person (i.e., to make assumptions) is ascribed to an abstract principle. In other words, a human power is reified to an abstract entity, which is according to this theory - possessed by the human, and this entity is said to act in a similar way as humans do (the mereological fallacy) [Bennett \& Hacker, 2003]. However, principles are not able to think or to assume something and they are not logically appropriate subjects for psychological predicates [see also Wittgenstein, 1953]. This is not only a classical category mistake [Ryle, 1949], but it also leads to the disposition that one conceives of this ability as an all-or-nothing ability (i.e., one either possesses the principle or not, as a principle cannot be possessed half) and an independently existing mechanism, which can be implemented into the mind (like a software module can be implemented into a computer). This raises the probability that one ignores the developmental trajectory that needs to be given so that a particular cognitive ability can develop, and as a consequence one easily oversees the implicit assumptions that one makes when accepting this proposition.

Moreover, this principle is seen as the mechanism subserving infants' evaluation of the efficiency of others' actions. The resulting problem is clearly described by Hacker: 'If one thinks of powers as being kinds of things, then one will be prone to view the relation between a power and its actualization as a causal, rather than a logical, relation' [Hacker, 2010, p. 101]. In other words, if we assume that X has the power to Y (e.g., evaluate the efficiency of others' actions) and if we reify this ability to a thing-like being (e.g., a principle), we commit a fallacy when we refer to this thing-like being in order to explain why $\mathrm{X}$ is able to perform action $\mathrm{Y}$. That means, if it is suggested that infants assess the efficiency of others' actions, then referring to the principle of rational action when being asked to explain this ability (instead of elucidating the developmental pathway of this ability) is no explanation at all. In other words, the authors just name the principle, but do not explain how it could work. The principle of rational ac- 
tion is not the cause of someone's ability to evaluate the efficiency of others' actions (and can therefore not be cited as an explanation of this ability), but is nothing else than a conceptually confused way (i.e., a reification) of suggesting that someone is able to evaluate others' actions without explaining how one is able to do $\mathrm{so}^{3}$.

These considerations show that introducing the principle of rational action into developmental theorizing leads to severe conceptual confusions. To avoid these problems, it would be more appropriate to just talk of the ability to assess the efficiency of others' action, and to investigate when and how this ability develops.

\section{Conclusion}

The present analysis not only clarifies our understanding of the neurocognitive mechanisms that might underlie imitation in infancy, but also demonstrates the usefulness and fruitfulness of theoretical and conceptual analyses as a tool in developmental and cognitive psychology [Hacker, 2010; Müller \& Giesbrecht, 2008]. In particular, it suggests that more attention needs to be given to analyses of the conceptual preconditions that must be fulfilled to attribute a certain competency to an organism and thus to determine the developmental prerequisites from which complex behavior develops [e.g., Campbell \& Richie, 1983]. If empirical research suggests that an organism does not possess the necessary cognitive prerequisites for a particular competency, then it renders it very unlikely that the organism possesses this competency. Further progress in theory formation in developmental and cognitive psychology is thus expected from careful theoretical analyses.

Such an analysis might also be useful in other terrains of developmental psychology. For example, the concept of intention reading has been discussed as a main mechanism or key ability in infants' understanding of others' actions [Luo \& Baillargeon, 2010]. Yet, it is not clear what exactly is meant by intention reading or intention understanding, and how one (e.g., a preverbal infant) should be able to engage in intention reading. A careful conceptual analysis is needed to clarify the possible meaning(s) of the concept in the literature and the prerequisites that an organism must meet to be able to engage in such an activity. Such a clarification would also promise progress in this hotly disputed area of research.

To sum up, research in the last decade has suggested that 1-year-old infants already imitate rationally. However, the ability to imitate rationally rests conceptually on other cognitive prerequisites such as the ability to perceive others' action capabilities or the ability to reason counterfactually. The empirical findings that infants do not possess these competencies suggest that it is not rational to assume that infants imitate rationally.

\section{Acknowledgements}

For feedback on an earlier version of the manuscript I am thankful to Angela Khadar and Christine Fawcett.

\footnotetext{
${ }^{3}$ It should be noted that the introduction of a principle in place of psychological processes is not unique to imitation in infancy. Similar considerations can be found, for example, in theories of language acquisition [Chomsky, 1980; Markman, 1990] and infants' physical knowledge [Baillargeon, 2008].
}

Is It Rational to Assume that Infants Imitate Rationally?
Human Development 2012;55:107-121 


\section{References}

Adolph, K.E., \& Avolio, A. (2000). Walking infants adapt locomotion to changing body dimensions. Journal of Experimental Psychology: Human Perception and Performance, 26, 1148-1166.

Adolph, K.E., \& Berger, S. (2006). Motor development. In W. Damon \& R. Lerner (Series Eds.), D. Kuhn \& R.S. Siegler (Vol. Eds.), Handbook of child psychology. Vol. 2: Cognition, perception, and language (6th ed., pp. 161-213). New York: Wiley.

Adolph, K.E., \& Robinson, S.R. (2008). In defense of change processes. Child Development, 79, 1648 1653.

Apperly, I.A., \& Butterfill, S.A. (2009). Do humans have two systems to track beliefs and belief-like states? Psychological Review, 116, 953-970.

Baillargeon, R. (2008). Innate ideas revisited: For a principle of persistence in infants' physical reasoning. Perspectives on Psychological Science, 3, 2-13.

Baker, C.L., Saxe, R.R., \& Tenenbaum, J.B. (2009). Action understanding as inverse planning. Cognition, $113,329-349$.

Baldwin, J.M. (1968). Mental development in the child and race (3rd ed.). New York: Augustus M. Kelley. (Original work published in 1906.)

Barresi, J., \& Moore, C. (1996). Intentional relations and social understanding. Behavioral and Brain Sciences, 19, 107-122.

Beck, S.R., Riggs, K.J., \& Gorniak, S.L. (2009). Relating developments in children's counterfactual thinking and executive functions. Thinking and Reasoning, 15, 337-354.

Beck, S.R., Robinson, E.J., Carroll, D.J., \& Apperly, I.A. (2006). Children's thinking about counterfactuals and future hypotheticals as possibilities. Child Development, 77, 413-426.

Bennett, M.R., \& Hacker, P.M.S. (2003). Philosophical foundations of neuroscience. Malden: Blackwell.

Bering, J.M., \& Povinelli, D.J. (2003). Comparing cognitive development. In D. Maestripieri (Ed.), Primate psychology (pp. 205-233). Cambridge: Harvard University Press.

Brandom, R.B. (1994). Making it explicit. Reasoning, representing, and discursive commitment. Harvard: University Press.

Brandom, R.B. (2009). Reason in philosophy: Animating ideas. Cambridge: Harvard Press.

Brownell, C.A., \& Koop, C. (Eds.) (2007). Socioemotional development in the toddler years: Transitions and transformations. New York: Guilford Press.

Brownell, C.A., Nichols, S.R., Svetlova, M., Zerwas, S., \& Ramani, G. (2010). The head bone's connected to the neck bone: When do toddlers represent their own body topography? Child Development, 81 , 797-810.

Brownell, C.A., Zerwas, S., \& Ramani, G.B. (2007). 'So big': The development of body self-awareness in toddlers. Child Development, 78, 1426-1440.

Buttelmann, D., Carpenter, M., Call, J., \& Tomasello, M. (2007). Enculturated chimpanzees imitate rationally. Developmental Science, 10, F31-F38.

Buttelmann, D., Carpenter, M., Call, J., \& Tomasello, M. (2008). Rational tool use and tool choice in human infants and great apes. Child Development, 79, 609-626.

Calvo-Merino, B., Glaser, D.E., Grèzes, J., Passingham, R.E., \& Haggard, P. (2005). Action observation and acquired motor skills: An fMRI study with expert dancers. Cerebral Cortex, 15, $1243-$ 1249.

Campbell, R.L., \& Richie, D.M. (1983). Problems in the theory of developmental sequences: Prerequisites and precursors. Human Development, 26, 156-172.

Carpendale, J.E.M., \& Lewis, C. (2004). Constructing an understanding of the mind: The development of children's understanding of mind within social interactions. Behavioral and Brain Sciences, 27, 79-150.

Chomsky, N. (1980). Rules and representations. New York: Columbia University Press.

Csibra, G., \& Gergely, C. (2007). 'Obsessed with goals': Functions and mechanisms of teleological interpretation of actions in humans. Acta Psychologica, 124, 60-78.

Csibra, G., \& Gergely, G. (2009). Natural pedagogy. Trends in Cognitive Sciences, 13, 148-153.

Csibra, G., Gergely, G., Bíró, S., Koós, O., \& Brockbank, M. (1999). Goal attribution without agency cues: The perceptions of 'pure reason' in infancy. Cognition, 72, 237-267.

De Bruin, L.C., \& Newen, A. (2012). An association account of false belief understanding. Cognition, $123,240-259$.

Elsner, B. (2007). Infants' imitation of goal-directed actions: The role of movements and action effects. Acta Psychologica, 124, 44-59.

Ewert, O.M. (1983). Eine historische Nachbemerkung zu Neuberger, Merz und Selg: Imitation bei Neugeborenen - eine kontroverse Befundlage. Zeitschrift für Entwicklungspsychologie und Pädagogische Psychologie, 15, 277-279. 
Gergely, G., Bekkering, H., \& Kiraly, I. (2001). Rational imitation of goal-directed actions in 14-montholds. In J.D. Moore \& K. Stenning (Eds.), Proceedings of Cogsci 2001 (pp. 309-315). London: LEA.

Gergely, G., Bekkering, H., \& Kiraly, I. (2002). Rational imitation in preverbal infants. Nature, 415, 755.

Gergely, G., \& Csibra, G. (2003). Teleological reasoning in infancy: The naïve theory of rational action. Trends in Cognitive Sciences, 7, 287-292.

Gopnik, A., \& Schulz, L. (2004). Mechanisms of theory formation in young children. Trends in Cognitive Sciences, 8, 371-377.

Guillaume, P. (1925). L'imitation chez l'enfant. Paris: Alcan.

Hacker, P.M.S. (2010). Human nature: The categorical framework. Chichester: Wiley-Blackwell.

Haith, M.M. (1998). Who put the cog in infant cognition: Is rich interpretation too costly? Infant Behavior and Development, $21,167-179$.

Hamlin, J.K., Wynn, K., \& Bloom, P. (2007). Social evaluation by preverbal infants. Nature, 450, 557559.

Harr, R., \& Tissaw, M.A. (2005). Wittgenstein and psychology: A practical guide. Aldershot: Ashgate Publishing.

Heyes, C.M. (2001). Causes and consequences of imitation. Trends in Cognitive Sciences, 5, 253-261.

Heyes, C.M. (2009). Evolution, development and intentional control of imitation. Philosophical Transactions of the Royal Society of London. Series B, Biological Sciences, 364, 2293-2298.

Hommel, B. (2009a). Action control according to TEC (theory of event coding). Psychological Research, $73,512-526$.

Hommel, B. (2009b). Conscious and unconscious control of spatial action. In W.P. Banks (Ed.), Encyclopedia of consciousness (pp. 171-181). Oxford: Elsevier.

Hommel, B., Müsseler, J., Aschersleben, G., \& Prinz, W. (2001). The theory of event coding (TEC): A framework for perception and action planning. Behavioral and Brain Sciences, 24, 849-878.

Jones, S.S. (2007). Imitation in infancy. The development of mimicry. Psychological Science, 18, 593-599.

Jones, S.S. (2009). The development of imitation in infancy. Philosophical Transactions of the Royal Society of London. Series B, Biological Sciences, 364, 2325-2335.

Jones, S.S., \& Yoshida, H. (2011). Imitation in infancy and the acquisition of body knowledge. In V. Slaughter \& C. Brownell (Eds.). Early development of body representations. Cambridge: Cambridge University Press.

Kaminski, J., Nitzschner, M., Wobber, V., Tennie, C., Bräuer, J., Call, J., \& Tomasello, M. (2011). Can dogs distinguish rational from irrational acts? Animal Behaviour, 81, 195-203.

Kiraly, I. (2009). The effect of the model's presence and of negative evidence on infants' selective imitation. Journal of Experimental Child Psychology, 102, 14-25.

Klossek, U.M.H., Russell, J., \& Dickinson, T. (2008). The control of instrumental action following outcome devaluation in young children. Journal of Experimental Psychology: General, 137, 39-51.

Kovács, Á.M., Téglás, E., \& Endress, A.D. (2010). The social sense: Susceptibly to others' beliefs in human infants and adults. Science, 330, 1830-1834.

Knudsen, B., \& Liszkowski, U. (2012). Eighteen- and 24-month-old infants correct others in anticipation of action mistakes. Developmental Science, 15, 113-122.

Kuhlmeier, V.A., Wynn, K., \& Bloom, P. (2003). Attribution of dispositional states by 12 -month-olds. Psychological Science, 14, 402-408.

Kuhn, T.S. (1962). The structure of scientific revolutions. Chicago: University of Chicago Press.

Luo, Y. (2010). Do 8-month-old infants consider situational constraints when interpreting others' gaze as goal-directed action? Infancy, 15, 392-419.

Luo, Y., \& Baillargeon, R. (2010). Toward a mentalistic account of early psychological reasoning. Current Directions in Psychological Science, 19, 301-307.

Markman, E.M. (1990). Constraints children place on word meaning. Cognitive Science, 14, 57-77.

Meltzoff, A.N., \& Moore, M.K. (1977). Imitation of facial and manual gestures by human neonates. Science, 198, 75-78

Meltzoff, A.N., \& Moore, M.K. (1997). Explaining facial imitation: A theoretical model. Early Development and Parenting, 6, 179-192.

Moore, C. (2006). The development of commonsense psychology. Mahwah: LEA.

Moore, C., Mealiea, J., Garon, N., \& Povinelli, D. (2007). The development of body self-awareness. Infancy, 11, 157-174.

Müller, U., \& Giesbrecht, G. (2008). Methodological and epistemological issues in the interpretation of infant cognitive development. Child Development, 79, 1654-1658.

Nachev, P., \& Hacker, P.M.S. (2010). Covert cognition in the persistent vegetative state. Current Opinion in Neurobiology, 91, 68-75.

Nelson, C.A. (2001). The development and neural bases of face recognition. Infant and Child Development, 10, 3-18.

Nielsen, M. (2006). Copying actions and copying outcomes: Social learning through the second year. Developmental Psychology, 42, 555-565.

Is It Rational to Assume that Infants Imitate Rationally?
Human Development 2012;55:107-121
119 
Onishi, K.H., \& Baillargeon, R. (2005). Do 15-month-old infants understand false beliefs? Science, 308, $255-258$.

Overton, W.F. (1998). Developmental psychology: Philosophy, concepts, and methodology. In W. Damon (Series Ed.) \& R.M. Lerner (Vol. Ed.), Handbook of child psychology. Vol. 1: Theoretical models of human development (5th ed., pp. 107-188). New York: Wiley.

Paulus, M. (2011). Imitation in infancy: Conceptual considerations. Theory \& Psychology, 21, 849-856.

Paulus, M., Hunnius, S., van Wijngaarden, C., Vrins, S., van Rooij, I., \& Bekkering, H. (2011a). The role of frequency information and teleological reasoning in infants' and adults' action prediction. $D e-$ velopmental Psychology, 47, 976-983.

Paulus, M., Hunnius, S., Vissers, M., \& Bekkering, H. (2011b). Imitation in infancy: Rational or motor resonance? Child Development, 82, 1047-1057.

Paulus, M., Hunnius, S., Vissers, M., \& Bekkering, H. (2011c). Bridging the gap between the other and me: The functional role of motor resonance and action effects in infants' imitation. Developmental Science, 14, 901-910.

Paulus, M., \& Moore, C. (2011). Whom to ask for help? Children's developing understanding of other people's action capabilities. Experimental Brain Research, 211, 593-600.

Perner, J., \& Ruffman, T. (2005). Psychology. Infants' insight into the mind: how deep? Science, 308, $214-216$

Perner, J., Sprung, M., \& Steinkogler, B. (2004). Counterfactual conditionals and false belief: A developmental dissociation. Journal of Cognition and Development, 19, 179-201.

Piaget, J. (1954). The construction of reality in the child. New York: Basic Books.

Piaget, J. (1962). Play, dreams and imitation in childhood. New York: Norton.

Povinelli, D.J., Bering, J.M., \& Giambrone, S. (2000). Towards a science of other minds: Escaping the argument by analogy. Cognitive Science, 24, 509-541.

Povinelli, D.J., \& Giambrone, S. (1999). Inferring other minds: Failure of the argument by analogy. Philosophical Topics, 27, 167-201.

Preyer, W. (1980). Die Seele des Kindes. Beobachtungen über die geistige Entwicklung des Menschen in den ersten Lebensjahren (3rd ed.). Leipzig: Grieben.

Rafetseder, E., Cristi-Vargas, R., \& Perner, J. (2010). Counterfactual reasoning: Developing a sense of 'nearest possible world'. Child Development, 81, 376-389.

Rakoczy, H. (2008). Pretence as individual and collective intentionality. Mind and Language, 23, 499517.

Rakoczy, H. (2012). Do infants have a theory of mind? British Journal of Developmental Psychology, 30, $59-74$.

Range, F., Virnayi, Z., \& Huber, L. (2007). Selective imitation in domestic dogs. Current Biology, 17, $868-872$.

Ray, E., \& Heyes, C.M. (2011). Imitation in infancy: The wealth of the stimulus. Developmental Science, $14,92-105$

Ridderinkhof, K.R., Forstmann, B.U., Wylie, S.A., Burle, B., \& van den Wildenberg, W.P. M. (2011) Neurocognitive mechanisms of action control: Resisting the call of the Sirens. Wiley Interdisciplinary Reviews: Cognitive Science, 2, 174-192.

Ridderinkhof, K.R., van den Wildenberg, W.P.M., Segalowitz, S.J., \& Carter, C.S. (2004). Neurocognitive mechanisms of cognitive control: The role of prefrontal cortex in action selection, response inhibition, performance monitoring, and reward-based learning. Brain and Cognition, 56, 129 140 .

Ryle, G. (1949). The concept of mind. Chicago: University Press.

Schwier, C., van Maanen, C., Carpenter, M., \& Tomasello, M. (2006). Rational imitation in 12-monthold infants. Infancy, 10, 303-311.

Siegal, M., \& Varley, R. (2008). If we could talk to the animals. Behavioral and Brain Sciences, 31, 146147.

Sodian, B. (2011). Theory of mind in infancy. Child Development Perspectives, 5, 39-43.

Thoermer, C., Sodian, B., Vuori, M., Perst, H., \& Kristen, S. (2012). Continuity from an implicit to an explicit understanding of false belief from infancy to preschool age. British Journal of Developmental Psychology, 30, 172-187.

Tissaw, M.A. (2007). Making sense of neonatal imitation. Theory \& Psychology, 17, 217-242.

Tomasello, M., Carpenter, M., Call, J., Behne, T., \& Moll, H. (2005). Understanding and sharing intentions: The origins of cultural cognition. Behavioral and Brain Sciences, 28, 675-691.

van Geert, P. (2004). Dynamic modeling of cognitive development. Time, situatedness and variability. In A. Demetriou \& A. Raftopoulos (Eds.), Emergence and transformation in the mind: Modeling and measuring cognitive change (pp. 354-378). Mawah: Erlbaum.

van Quine, W. (1960). Word and object. Harvard: MIT Press.

Verschoor, S.A., Weidema, M., Biro, S., \& Hommel, B. (2010). Where do action goals come from? Evidence for spontaneous action-effect binding in infants. Frontiers in Psychology, 1, 201. 
Vonk, J., \& Subiaul, F. (2009). Do chimpanzees know what others can and cannot do? Reasoning about 'capability'. Animal Cognition, 12, 267-286.

Wittgenstein, L. (1953). Philosophical investigations. Oxford: Basil Blackwell.

Zelazo, P.D., Carlson, S.M., \& Kesek, A. (2008). Development of executive function in childhood. In C.A. Nelson \& M. Luciana (Eds.), Handbook of developmental cognitive neuroscience (2nd ed., pp. 553-574). Cambridge: MIT Press.

Zelazo, P.D., Müller, U., Frye, D., \& Marcovitch, S. (2003). The development of executive function in early childhood. Monographs of the Society for Research in Child Development, 68, Serial No. 274.

Zmyj, N., Daum, M.M., \& Aschersleben, G. (2009). The development of rational imitation in 9- and 12-month-old infants. Infancy, 14, 131-141.

Is It Rational to Assume that Infants Imitate Rationally?
Human Development 2012;55:107-121 